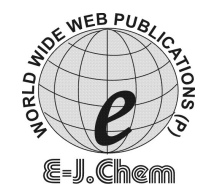

http://www.e-journals.net

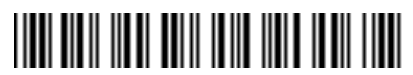

ISSN: 0973-4945; CODEN ECJHAO

E-Journal of Chemistry

Vol. 4, No. 4, pp. 457-460, October 2007

\title{
Microwave Assisted Synthesis of Phenol-Formaldehyde Resole
}

\author{
Department of Pure and Applied Chemistry, \\ Maharshi Dayanand Saraswati University, Ajmer-305009. \\ \#Department of Chemistry, M.P.S. Government College, Chittorgarh. \\ subhash_bajia@indiatimes.com; chiya_f@yahoo.co.in
}

Received 09 December 2006; Accepted 10 January 2007

\begin{abstract}
An efficient synthesis of phenol-formaldehyde resin has been achieved by using conventional as well as microwave irradiation. Resin samples were tested for their physical and chemical properties. The structures of the resins have been supported by their spectral analysis.
\end{abstract}

Keywords: Phenol-formaldehyde resin, Microwave irradiation, Free formaldehyde.

\section{Introduction}

Phenolic resole are the most useful thermosetting materials for the manufacture of composite panels ${ }^{1}$, based on wood such as plywood. After curing the resole resin is a solid, insoluble, rigid material with a high fire resistance, long term thermal, mechanical stability, high strength, low toxic and excellent insulating properties.

Microwave irradiation is well known to promote the synthesis of a variety of organic compounds, where chemical reactions are accelerated because of selective absorption of microwave by polar molecules ${ }^{2}$. As a part of our programme towards the non traditional approach to the experimental set up of organic reactions, the concept of "Microwave induced Organic Reaction Enhancement" (MORE) chemistry has been utilized for rapid, sustainable and efficient synthesis. Microwave assisted organic synthesis ${ }^{3-7}$ has attracted attention in recent years due to enhanced reaction rates, high yields, improved purity, ease of work up after the reaction and eco-friendly reaction conditions compared to the conventional methods. 
The present work reveals the comparative aspects of synthesis of phenolformaldehyde resin (conventional and microwave) and their characterization. The properties such as viscosity, gel time, solid content and free formaldehyde content are measured of the synthesized resin.

\section{Experimental}

Reagent grade chemicals were used after distillation. Viscosity was measured according to ASTM D1084, Method ${ }^{8}$ with a Brookfield Digital Viscometer. An efficient synthesis reaction under microwave irradiations was carried out in Microwave Oven Model LG MS$194 \mathrm{~W}$ operating at $160 \mathrm{~W}$ generating $2450 \mathrm{MH}_{\mathrm{Z}}$ frequency. Internal temperature of reaction mixture was measured on Mini Gun Type Non-Contact I.R. thermometer. FTIR spectra were recorded with a Perkin-Elmer $16 \mathrm{PC}$ spectrometer using $\mathrm{KBr}$ pellets. The ${ }^{13} \mathrm{C}$ NMR spectra were obtained with a Buker WM 250 spectrometer $\left(68.69 \mathrm{MH}_{\mathrm{Z}}\right)$ using deutrated methanol as solvent at $37{ }^{\circ} \mathrm{C}$. Resin solid content ${ }^{9}$ were determined by heating a $1 \mathrm{gm}$. sample at $125{ }^{\circ} \mathrm{C}$ for $1.75 \mathrm{~h}$. The percentage of free formaldehyde content in resin was determined using a modified version of Walker' ${ }^{10}$ hydroxylamine hydrochloride and sodium sulfide methods.

\section{Investigation of the synthesis of phenol-formaldehyde resin:}

Under conventional method:

These resins were synthesized by methods reported earlier. ${ }^{11-13}$ The phenol-formaldehyde resins were synthesized in different molar ratio by adding phenol (94\%) and formaldehyde (37\% aqueous solution) in three neck flask. The $\mathrm{pH}(9.0)$ was adjusted by using aqueous caustic $(20 \%)$ solution. After this, the reaction mixture was heated to $90{ }^{\circ} \mathrm{C}$ over a period of 30 minutes. The resultant mixture was refluxed for $2 \mathrm{~h}$. The free formaldehyde content in the resin at different time interval was checked and the resin was cooled (Scheme-I).

\section{Under microwave irradiation}

The phenol-formaldehyde resin was synthesized by condensing phenol and formaldehyde in the presence of sodium hydroxide ( $\mathrm{pH}$ 9.0). The reaction was carried out in Erlen-Meyer flask capped with a funnel under microwave irradiation at 160 watt in microwave oven for the specific period of time. The complication of the reaction was monitored by determination of the free formaldehyde content. The internal temperature of reaction mixture was measured by Non-Contact I.R. thermometer.

\section{Determination of free formaldehyde}

The percentages of the free formaldehyde in the resin were determined using a modified version of Walker's hydroxylamine hydrochloride method. Approximately $3 \mathrm{~g}$. of resin were diluted with $25 \mathrm{~mL}$ of water and $\mathrm{pH}$ was adjusted to 4.0 using $0.1 \mathrm{M} \mathrm{HCl}$. Thirty $\mathrm{mL}$ of hydrolamine hydrochloride $(0.5 \mathrm{M}, \mathrm{pH} 4.0)$ were added and stirred for 10 minutes and free formaldehyde was determined by back titration at $\mathrm{pH} 4.0$ using $0.1 \mathrm{M}$ aqueous sodium hydroxide.

\section{Spectral data of synthesized resin}

${ }^{13} \mathrm{C}$ NMR Spectra : The assessments are as follows

36 and 41 ppm for 2, 4 and 4, 4-methylene links, respectively; 61 and 65 ppm for 2 and 4hydroxymethyls, respectively; $88 \mathrm{ppm}$ for various forms of formaldehyde; 117 and $121 \mathrm{ppm}$ for unsubstituted 2 and 4-phenolic ring position, respectively; $127 \mathrm{ppm}$ for unsubstituted 3, 5 and substituted 2, 4 phenolic ring positions and $160 \mathrm{ppm}$ for phenolic -OH positions. 


\section{Fourier Transform Infrared Spectroscopy}

The deformation vibrations of $-\mathrm{C}-\mathrm{H}$ bonding in aromatic units correspond to the absorption bands in the $600-900 \mathrm{~cm}^{-1}$. The bands at 997 and $1025 \mathrm{~cm}^{-1}$, characteristic of C-O bonds in hydroxymethyl groups attached to aromatic ring. The bands at $1060 \mathrm{~cm}^{-1}$, characteristic of C-O bands in an ether group. The band at $1110 \mathrm{~cm}^{-1}$, characteristic of the deformation vibration of aromatic $-\mathrm{CH}$ bonds, $1205 \mathrm{~cm}^{-1}$ for phenolic hydroxyl and at $1275 \mathrm{~cm}^{-1}$ for sodium salt of phenolic hydroxyl. The methylene bridge between to aromatic rings are shows absorption at $1450 \mathrm{~cm}^{-1}$ for para-para, $1460 \mathrm{~cm}^{-1}$ for ortho-ortho and $1480 \mathrm{~cm}^{-1}$ for ortho-para.

\section{Result and Discussion}

\section{Comparative profile of synthesis}

Phenol-formaldehyde resins were prepared by condensing phenol and formaldehyde in basic medium. In view of long reaction time, moderate yields, tedious work up after the reaction in conventional method, a relatively more versatile yet simplified procedure was perceived, in microwave irradiation. Microwave synthesis has received attention as a new strategy for organic synthesis due to the fact that many reactions seem to proceed with much alacrity under such conditions as opposed to the corresponding thermal-assisted reactions. The strategy worked well affording the desired product in improved yields in significantly lower reaction time. To ensure the contribution of specific microwave effect, the results obtained under microwave irradiation were extrapolated to conventional heating. Reactions mentioned in Table 1 were examined by simply heating under the same conditions (temperature, pressure, viscosity and $\mathrm{pH}$ ) as mentioned in the typical procedure with microwave irradiation. Under microwave irradiation enhanced dipole-dipole interaction caused the instantaneous condensation of reactant to afford phenolformaldehyde resin in a very short time.

Table 1. Comparative study for the synthesis of phenol-formaldehyde resin.

\begin{tabular}{ccccccccccc}
\hline \multicolumn{1}{c}{ Conventional method } \\
\hline $\begin{array}{c}\text { Molar } \\
\text { ratio }\end{array}$ & $\begin{array}{c}\text { Time } \\
\text { h }\end{array}$ & $\begin{array}{c}\text { Temp. } \\
{ }^{0} \mathrm{C}\end{array}$ & $\begin{array}{c}\text { F.F. } \\
\text { Cont. } \\
\%\end{array}$ & $\begin{array}{c}\text { Yield } \\
\%\end{array}$ & $\begin{array}{c}\text { Solid } \\
\text { Content } \\
\%\end{array}$ & $\begin{array}{c}\text { Time } \\
\text { min }\end{array}$ & $\begin{array}{c}\text { Temp. } \\
{ }^{0} \mathrm{C}\end{array}$ & $\begin{array}{c}\text { F.F. }^{\mathrm{b}} \\
\text { Cont. } \\
\%\end{array}$ & $\begin{array}{c}\text { Yield }^{\mathrm{c}} \\
\%\end{array}$ & $\begin{array}{c}\text { Solid } \\
\text { Content } \\
\%\end{array}$ \\
\hline $1: 1.5$ & 2.0 & Reflux & 1.0 & 65 & 37 & 4.5 & 90 & 0.1 & 69 & 45 \\
$1: 2.0$ & 2.0 & Reflux & 2.2 & 68.4 & 39 & 6.0 & 95 & 0.3 & 74 & 47 \\
$1: 3.0$ & 2.0 & Reflux & 3.5 & 72 & 43 & 4.0 & 92 & 0.2 & 78 & 55 \\
\hline
\end{tabular}

${ }^{\mathrm{a}}$ The final internal temperature of the reaction mixture was measured by Non-Contact I.R. Thermometer. ${ }^{b}$ Free formaldehyde content in the resin. ${ }^{c}$ Yield of final compound that exhibited physical and spectral properties in accordance with assigned structure.

\section{Reaction scheme-I}

During synthesis of phenol-formaldehyde resole two main reactions occur.

(I) Addition reaction; (II) Condensation reaction.

Step I. Addition reaction:

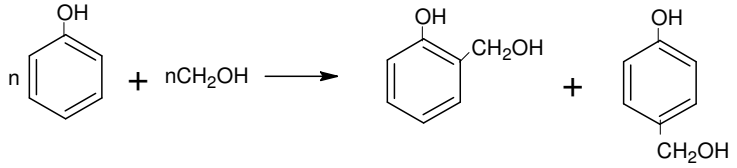


Step II. Condensation reaction:

a)

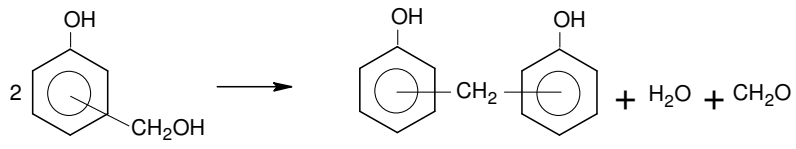

b)

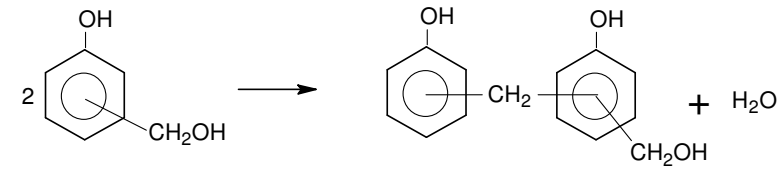

c)
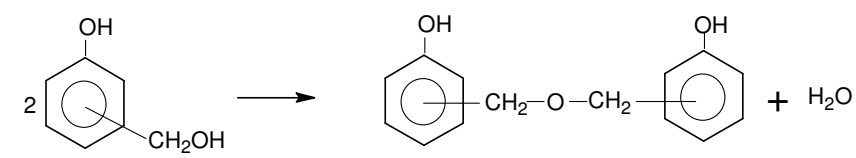

\section{Conclusions}

We have developed an economical, solvent free, very efficient microwave assisted protocol for the synthesis of phenol-formaldehyde resin which can be a viable alternative to the conventional synthesis. In all cases, a comparison of the reactions using conventional and microwave heating under same conditions. The resin synthesized by microwave irradiation has less free formaldehyde, more solid content.

\section{Acknowledgement}

Authors are thankful to Head, Department of Pure and Applied Chemistry, M.D.S.University, Ajmer for providing necessary laboratory facilities, to the Director CDRI Lucknow, India for providing spectral data. Authors also express thanks to UGC, New Delhi, India for providing financial support to one of them (S.C.Bajia).

\section{Reference}

1. George E, Myers, Alfred W, Christiansen, Robert L Geimer, Robart A. Follensbee and James A Koutskey, J Applied Polymer Science, 1991,43.237.

2. Hermken S P, Ottenheijam H and Ress D, Tetrahedron, 1997,53,5643.

3. Prashant Kriplani, Pawan Swarnkar, Rinku Maheshwari, Ojha K G, E-J.Chem, 2006, 3(13), 307.

4. Rajanarendar E and Karunakar E, Indian J Chem. 2006, 43,805.

5. Caddick S, Tetrahedron, 1995,51,10403

6. Kuhnert N, Angew Chem Int Ed. 2002, 41, 1863.

7. Abramovitch R A, Org Pep Proc Int, 1991.23,683.

8. ASTM, Annual Book of ASTM Standards, D 1084-88, 1991, Vol.15, American Society for Testing and Materials, Philadelphia, Pennsylvania.

9. West Coast Manufactures Association Method 2.2, Determination of percent non volatile content in liquid phenolic resins, Seattle, WA, 1957.

10. Walker J F, Formaldehyde, Krieger Publishing Co., Huntington, New York, 1975, p 493,

11. Gabilondo N, Martin M D, Mondragon I and Echeverria J M, High Performance Polymers, 2002, 14, 415.

12. Young-Kyu Lee, Dae-Jun Kim, Hyun-Joong Kim, Teak-Sung Hwang and Miriam Rafailovich, J Applied Polymer Science, 2003, 89, 2589.

13. Waage S K, Gardner D J and Elder T J, J Applied Polymer Science, 1991, 42, 273. 


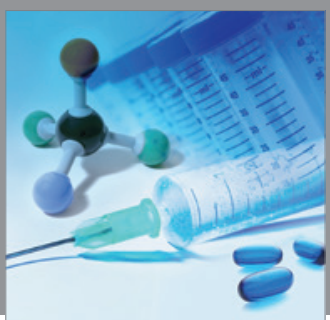

International Journal of

Medicinal Chemistry

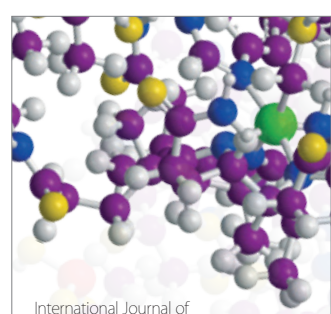

Carbohydrate Chemistry

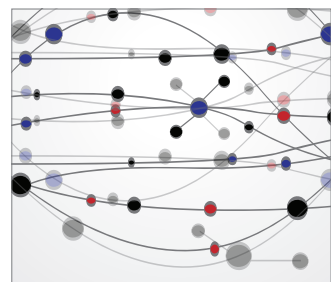

The Scientific World Journal
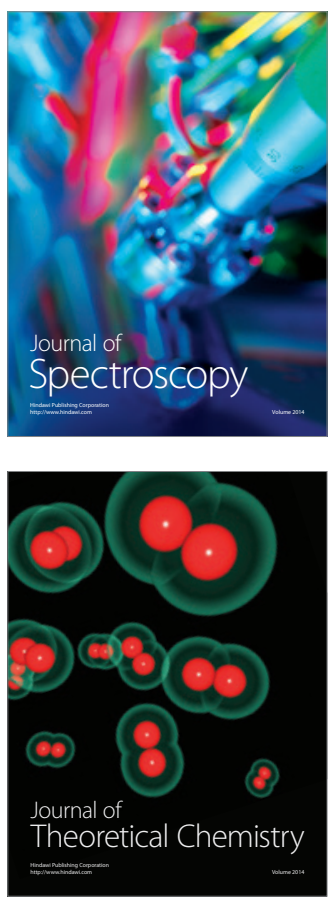
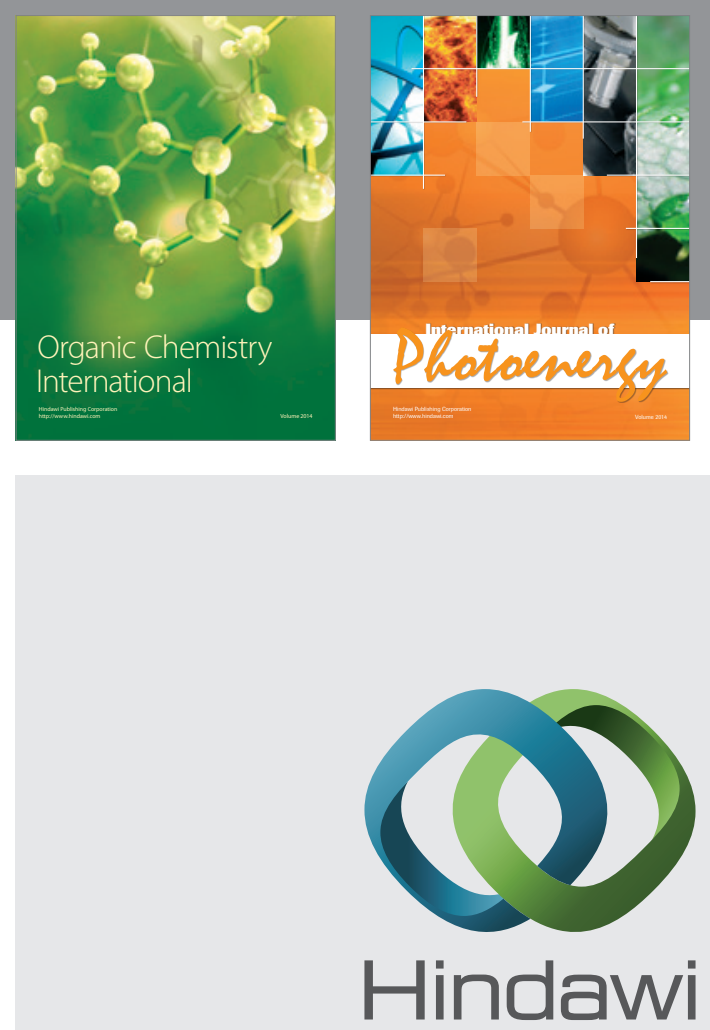

Submit your manuscripts at

http://www.hindawi.com
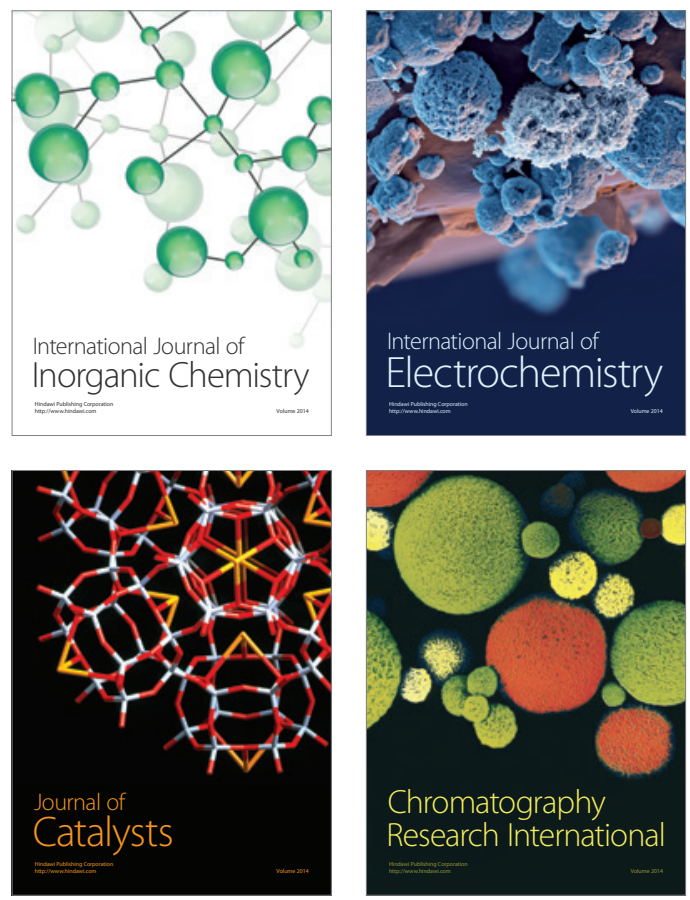
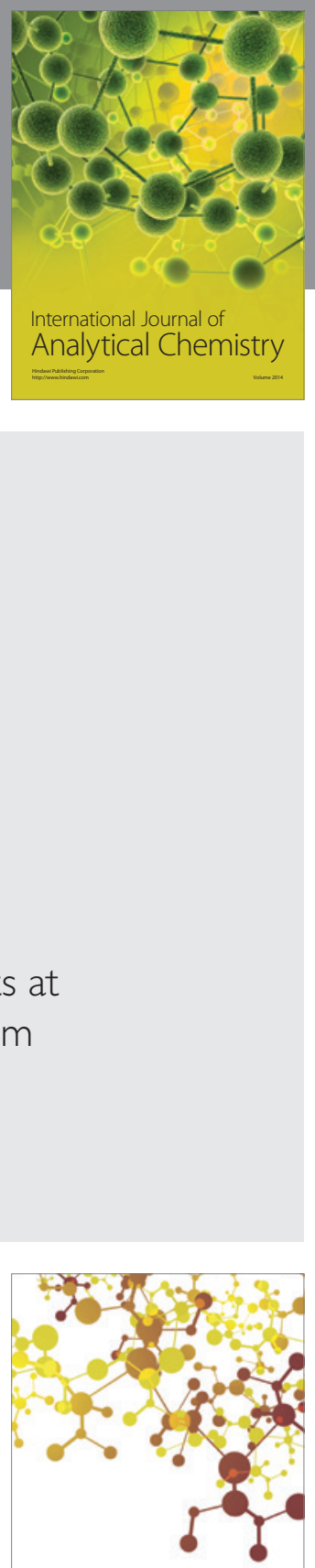

Journal of

Applied Chemistry
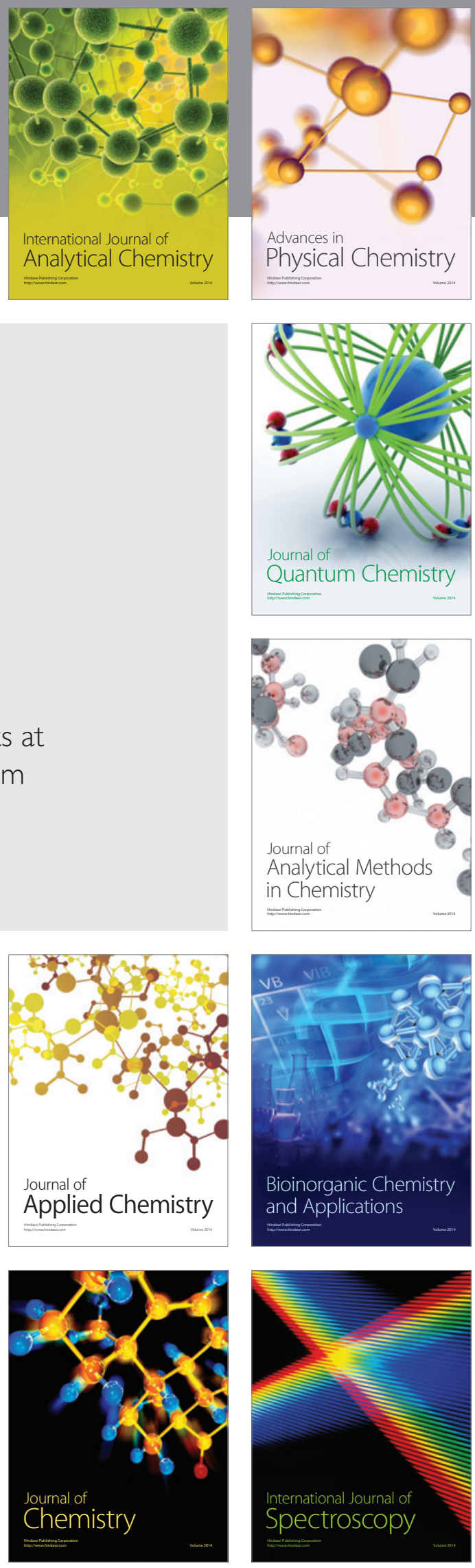